\title{
A PAIXÃO DOS MÁRTIRES DE ABITINA E O COMBATE AO DIABO: CONSTRUÇÃO DE IDENTIDADES NA CONTROVÉRSIA DONATISTA
}

\author{
Juliana Marques Morais ${ }^{1}$ (História Social - USP) \\ Prof. Doutor Julio Cesar Magalhães de Oliveira $^{2}$ (Orientador)
}

A Controvérsia Donatista foi um cisma que dividiu a Igreja africana no Império Romano Tardio por, pelo menos, três séculos. Uma parte importante das disputas esteve diretamente relacionada à negação e/ou afirmação das identidades coletivas reivindicadas pelos grupos que se autodenominavam católicos. Nesse trabalho buscamos identificar como e em quais contextos específicos, os cristãos envolvidos nas disputas suscitadas pela Controvérsia Donatista, buscaram moldar identidades coletivas em oposição aos seus adversários religiosos. A partir da análise da Paixão dos Mártires de Abitinia, procuramos compreender os usos estratégicos da demonização de adversários religiosos como parte do processo de construção/reconstrução das identidades coletivas, no contexto dos conflitos sectários que ocorreram no Norte da África no início do século V.

Palavras chaves: Martírio, combate ao Diabo, conflitos religiosos, identidades coletivas

\section{INTRODUÇÃO}

A Controvérsia Donatista foi um cisma que dividiu a Igreja africana no Império Romano Tardio por, pelo menos, três séculos ${ }^{3}$. A disputa entre os cristãos norteafricanos surgiu a partir de uma questão menor, envolvendo a eleição episcopal da cidade de Cartago, e se consolidou como cisma a partir da intervenção do primeiro imperador cristão, Constantino.

No início do século IV, com a morte do então bispo de Cartago, Mensúrio. Opondo-se ao resultado das eleições, setenta bispos da Numídia declararam inválida a ordenação de Ceciliano e elegeram Marjorino em seu lugar. Ceciliano era acusado de ter colaborado com as autoridades perseguidoras, ou se não, de ter sido ordenado por um traditor ${ }^{4}$, ou seja, aquele que nos tempos de perseguição entregou as Sagradas Escrituras ao perseguidor. Em seu lugar, os bispos da Numídia elegeram um bispo "puro", Marjorino, que após sua morte foi sucedido por Donato, o qual originou o nome do "partido donatista".

Com o fim das perseguições, era preciso saber a quem devolver as igrejas e propriedades tomadas pelo Império. Nesse sentido, era necessário identificar qual era a

\footnotetext{
${ }^{1}$ Doutoranda pela Programa de História Social (USP) e Bolsista CAPES.

${ }^{2}$ Professor de História Antiga do Departamento de História da USP.

${ }^{3}$ A controvérsia teve como ponto de partida a consagração de Ceciliano. A data precisa em que ocorreu a consagração ainda é motivo de discussão entre os historiadores. Uma datação mais tradicional aponta que os eventos que culminaram no cisma tenham ocorrido entre os anos de 311 e 313. Entretanto, novas pesquisas sugerem uma data anterior, entre os anos de 306/307 (MAGALHÃES DE OLIVEIRA, Inédito; SHAW, 2011). Ou ainda, 307/308, essa última defendia por Alan Dearn (2004). Não se sabe ao certo quando a Igreja Donatista deixou de existir, pois a partir da conquista Vândala há uma escassez de documentação. Sabe-se que em 569, o Papa Gregório escreveu uma carta ao Imperador Maurício reclamando da crescente influência do donatismo na Numídia (FREND, 2003, p. 2).

${ }^{4}$ Os bispos da Numídia acusavam Felix de Abthungi, responsável pela ordenação de Ceciliano, de ter colaborado com as autoridades imperiais nos tempos de perseguição, e de ter entregue as Sagradas Escrituras (DEARN, 2004, p. 1).
} 


\section{SEMINÁRIO DE PESQUISA EM CIÊNCIAS HUMANAS - SEPECH \\ Humanidades, Estado e desafios didático-científicos \\ Londrina, 27 a 29 de julho de 2016}

verdadeira Igreja africana. Quando a questão chega a Constantino, esse opta por reconhecer Ceciliano ${ }^{5}$ e seus partidários como os legítimos católicos e, ao fazer isso, não apenas nega a identidade católica ao grupo oponente, como também os coloca na situação de dissidentes (SHAW, 2011, p. 5-6).

Essa oposição entre donatistas e cecilianistas foi estudada por várias correntes historiográficas, que muitas vezes apontaram para razões étnicas ou sociais como motivo da dissidência. Alguns autores, ao se reportar à controvérsia, buscaram entender a Igreja donatista como um repositório da resistência púnica à dominação romana (FREND, 2003). Contrário a essas abordagens, autores como Peter Brown, defenderam que o motivo da divisão não era nem étnico, nem social, mas sim uma incongruência entre uma visão expansionista, amplamente defendida pelo bispo Agostinho, e uma ideia da Igreja dos eleitos, defendida pelos donatistas. Enquanto uma defendia que a Igreja era universal, devendo englobar pecadores e não pecadores, a ideia donatista era da Igreja como uma "Arca de Noé” (BROWN, 2005, p. 263-276). Era uma contradição entre uma Igreja que se pretendia ligada ainda aos ideais da Igreja primitiva, à causa dos mártires e à defesa do mal que a rodeava. Contra uma Igreja, que ao adotar uma abordagem mais moderada e realista, se pretendia universal, disposta a englobar todo o Império (CORNELL; MATTHEWS, 1996, p. 198). Na visão de Peter Brown, a oposição entre católicos e donatistas refletia visões coerentes, estritamente religiosas, do que deveria ser a Igreja.

Contudo, novas abordagens, como a proposta pelo historiador Brent D. Shaw (2011), demonstram que a oposição entre os dois grupos, de fato, não reflete questões sociais mais profundas como propunha Frend e outros. Mas, tampouco, apresentava visões tão coerentes como propunham historiadores como Brown. A oposição entre os grupos, bem com as bases que a sustentava, só foi construída ao longo da disputa, e estava intrinsicamente relacionada à construção das identidades dos grupos em conflito.

Essas abordagens surgem num contexto mais amplo de crítica à ideia de identidade fixa e normativa: ao contrário, valoriza-se hoje o caráter fluido, em constante construção, das identidades ${ }^{6}$. Com bem demonstrou Shaw (2011), as ideias defendidas pelas duas Igrejas, que serviam de base para o debate em torno da controvérsia, foram formuladas, ou reformuladas, ao longo do cisma, na medida em que os lados procuravam construir suas identidades enquanto grupo, e muitas vezes, se auto definirem em oposição ao outro. Como bem definiu Shibutani, a interação entre os grupos não ocorre tanto em termos do que eles são, mas a partir das concepções que formam um do outro. As concepções em si, não são duplicações da realidade, mas são construídas por meio de percepções seletivas (SHIBUTANI, 1966, p. 189).

Em muitos momentos dessa disputa, essa busca de identidade ${ }^{7}$ ocorre em função do "outro" enquanto malévolo e demoníaco, que faz uma franca oposição a "nós", os verdadeiros cristãos. Como bem advertiu Peter Burke (2004, p. 157):

\footnotetext{
${ }^{5}$ Para Constantino, Ceciliano era o bispo existente; portanto, decidiu apoiá-lo contra o que, aos olhos não africanos, pareciam ser queixas exageradas e provincianas (BROWN, 2005, p. 266).

${ }^{6}$ Sobre o assunto ver: NOGUEIRA, P.; FUNARI, P.P.A.; COLlINS, J. Identidades fluidas no Judaísmo e Cristianismo antigos. São Paulo: Annablume/FAPESP, 2010.

${ }^{7}$ Para uma reflexão sobre a importância da identidade em um grupo, e o modo pelo qual a identidade desse grupo pode ser criada em relação ou comparação a outros, ver: BURKE, P. Teoria e História Social. Bauru: Edusc, 2000.
} 


\section{SEMINÁRIO DE PESQUISA EM CIÊNCIAS HUMANAS - SEPECH \\ Humanidades, Estado e desafios didático-científicos \\ Londrina, 27 a 29 de julho de 2016}

Infelizmente, a maioria dos estereótipos de outros, era ou é hostil, desdenhosa, ou no mínimo condescendente. (...) os estereótipos muitas vezes tomam a forma de inversão da auto-imagem do espectador.

É a partir dessas reflexões que procuramos compreender, nesse artigo, os usos estratégicos da demonização de adversários religiosos como parte do processo de construção/reconstrução das identidades coletivas, no contexto dos conflitos sectários que ocorreram no Norte da África no início do século V. Para tanto, selecionamos para análise um documento do período: a Paixão dos Mártires de Abitinia, escrita por um redator donatista.

\section{PAIXÃO DOS MÁRTIRES DE ABITINA}

A Paixão dos Mártires de Abitina $^{8}$ é um texto que relata a prisão, o interrogatório e o julgamento de quarenta e nove cristãos que sofreram o martírio na cidade de Cartago no ano de 304. O documento narra a trajetória de um grupo de fiéis que, em descumprimento às ordens imperiais previstas no primeiro Édito de Diocleciano de 303, reuniu-se na colônia de Abitina, no Norte da África, para a celebração do culto dominical. Em Abitina, os cristãos foram presos pelos magistrados locais e levados a Cartago, onde foram interrogados e julgados pelo procônsul Anulino.

Esse texto foi citado pela primeira vez nas Atas da Conferência de Cartago, como parte do dossiê donatista (MAIER, 1987; RUIZ BUENO, 1962). A Conferência de Cartago, realizada nos dias $1^{\circ}, 3$ e 8 de junho de 411 , reuniu duzentos e oitenta e seis bispos católicos e, duzentos e sessenta e nove bispos donatistas. Convocada pelo imperador Honório, a principal finalidade da Conferência era suprimir o cisma e restaurar a unidade da Igreja Africana. Esse foi um evento de suma importância na história da controvérsia na medida em que mobilizou ambos os lados à reivindicarem uma identidade de "verdadeiros católicos". Mesmo tendo sido reconhecidos como a verdadeira Igreja da África, os cecilianistas precisavam legitimar sua posição, contestada desde o início (SHAW, 2011, p.544-586). Por isso a importância em se juntar "provas" que atestassem o porquê estavam certos, e os "outros" estavam errados.

A versão "original"' da Paixão dos Mártires de Abitina, tal qual foi apresentada pelos donatistas na Conferência de Cartago, e a data de sua confecção, infelizmente não é conhecida. $O$ texto que chegou até nós, é uma versão posterior que,

\footnotetext{
${ }^{8}$ Passio sanctorum Datiui et Saturnini presbyteri et aliorum (MAIER, 1987).

${ }^{9}$ A publicação de referência da passio, tal qual a conhecemos, aparece na famosa Patrologia Latina, coleção editada pelo francês Jacques-Paul Migne no século XIX, no qual foram publicadas duas versões distintas: a edição de Baluze ${ }^{9}$ de 1761, que continha o texto completo; e a edição de Dom Thierry Ruinart ${ }^{9}$ de 1689 , que apresentava apenas as partes do texto que Ruinart considerava "autênticas". Enquanto Baluze prezou por publicar na íntegra o texto a partir dos manuscritos que estava trabalhando, ao publicar a Paixão dos Mártires de Abitina, Ruinart retirou partes do texto como o prefácio, a parte final, e grande parte da introdução. Para Ruinart tratava-se de um texto originalmente católico, interpolado por um autor donatista, por isso decidiu cortar algumas passagens que considerava "adições suspeitas" (RUIZ BUENO, 1962, p.97). Para Alan Dearn (2004, p. 7), a publicação dessas duas versões é que deu margem a interpretações posteriores de que havia duas versões distintas da passio, uma católica e outra donatista, quando na verdade essa distinção surge apenas com a publicação de Ruinart.
} 


\section{SEMINÁRIO DE PESQUISA EM CIÊNCIAS HUMANAS - SEPECH \\ Humanidades, Estado e desafios didático-científicos \\ Londrina, 27 a 29 de julho de 2016}

muito provavelmente, foi redigida por um autor donatista no início do século $\mathrm{V}$, após a conferência de Cartago e, provavelmente, em resposta a ela (DEARN, 2014).

De fato, a maioria dos comentadores da fonte parece concordar que a redação do texto, pelo menos a sua versão final, seja do início do século $\mathrm{V}^{10}$, sendo escrita logo após a Conferência de Cartago. A maneira épica como o martírio é narrado, nos revela os indícios de uma escrita mais tardia, característica das legendas ${ }^{11}$ redigidas no início do século $\mathrm{V}$. A riqueza dos detalhes, principalmente no que se refere ao interrogatório, nos permite sugerir que o autor tenha utilizado textos anteriores para redigir sua narrativa (MAIER, 1987, p. 57-58). Para Magalhães de Oliveira (2010, p. 64), mesmo escrevendo muito depois dos acontecimentos de 304, o autor provavelmente dispunha das atas de um processo real, proveniente de arquivos públicos no momento em que compôs a passio $^{12}$.

Se por um lado é verdade que a unidade autoral e a datação do texto ainda são objetos de discórdia entre os comentadores da fonte, por outro, não nos resta dúvidas quanto a sua mensagem. O texto é, em suma, um instrumento a favor do donatismo (MAIER, 1987, p. 58). É, antes de tudo, um texto que fala para uma comunidade que, embora majoritária no Norte da África, foi colocada na ilegalidade, principalmente após a Conferência de Cartago, e que buscava dar sentido à sua experiência e reforçar sua identidade. Na medida em que, ao enaltecer a figura dos mártires como um exemplo do que era ser um bom cristão, o redator buscava entre os personagens do passado um modo de legitimar as posições dos donatistas no presente (MAGALHÃES DE OLIVEIRA, 2010, p. 62), ou seja, demonstrar porque eles eram os "verdadeiros católicos", e porque estavam certos em persistirem no cisma, mesmo contrário às leis imperiais, que após a Conferência de Cartago, os classificava não mais como cristãos dissidentes, mas como hereges.

Ao longo de toda a passio, o autor procura não apenas exaltar a imagem dos mártires, mas também denunciar as falhas dos traditores. Com bem ressaltou Brent D. Shaw (2011, p.71-72), assim como outros textos, a Paixão dos Mártires de Abitina era lida em voz alta todos os anos nas igrejas donatistas com o objetivo de provocar a imitação do comportamento correto. Dessa forma, os leitores deveriam estar preparados para morrem como mártires, evitando se tornar traidores. Essa era uma afirmação importante naquele momento, principalmente porque após 411 , às pressões imperiais pela unidade da Igreja se intensificaram, e foram muitas vezes entendidas pelos donatistas, como uma "nova" perseguição.

\footnotetext{
${ }^{10}$ Sobre as discussões em relação à datação do texto ver: DEARN, Alan. The Abitinian Martyrs and the Outbreak of the Donatist Schism, Journal of Ecclesiastical History, 55/1, 2004, pp. 1-18.

${ }^{11}$ Sobre as diferentes formas de redação desses textos ver: SIQUEIRA, Silvia M. A. Memórias das mulheres mártires: modelos de resistência e liberdade. Horizonte, Belo Horizonte, v. 4, n. 8, p. 60-76, jun. 2006. (p. 60).

${ }^{12}$ De maneira convincente, Magalhães de Oliveira (2010, p. 63-64) defendeu que, a menção aos nomes dos magistrados municipais, bem como a acusação de rapto feita ao decurião Dativo, que aparecem na passio, parecem pouco prováveis de terem sido completamente inventadas.
} 


\section{SEMINÁRIO DE PESQUISA EM CIÊNCIAS HUMANAS - SEPECH \\ Humanidades, Estado e desafios didático-científicos \\ Londrina, 27 a 29 de julho de 2016}

\section{IGREJA DOS MÁRTIRES X IGREJA DOS TRAIDORES}

O documento está estruturado em cinco partes. A primeira parte (I) é um breve prefácio, no qual o redator expõe suas intenções, que segundo ele é a de exaltar a figura dos mártires e condenar a ação dos traditores, algo que está presente em todo o texto. Em uma série de trechos, ele se remete à ideia de uma oposição entre Igreja dos Mártires, com o qual se identifica, e a Igreja dos traditores, que engloba seus adversários religiosos.

A Igreja dos Mártires, na concepção do autor, era formada pelo glorioso exército de Cristo que, ao sofrer o martírio, venceu o Diabo. Logo na introdução (II), o autor identifica a perseguição como uma guerra declarada pelo Diabo, no qual o exército do Senhor fora convocado a lutar:

Em tempos de Diocleciano e Maximiliano declarou o diabo a guerra aos cristãos do seguinte modo: exigiu que se entregassem os Santos Testamentos do Senhor e as Escrituras Divinas para serem queimadas [...]. Mas o exército do Senhor Deus não pode suportar um mandado tão feroz e, sentiu horror as ordens de sacrilégio. Assim, empunhando as armas, saiu à batalha para lutar, não tanto contra os homens quanto contra o diabo. ${ }^{13}$

Entretanto, o "exército de Deus" não era um lugar para todos. Em franco ataque aos seus opositores, o autor lembra que nem todos tinham alcançado a graça de ser um soldado de Cristo, uma vez que, enquanto alguns derramavam de bom grado seu sangue para defender as palavras de Deus, outros, por meio de um ato de covardia, entregavam às autoridades romanas as Sagradas Escrituras para serem queimadas nas fogueiras.

Após a introdução, segue-se um resumo da história dos mártires ainda em Abitina (III-IV). Segundo o autor, os quarenta e nove cristãos, entre eles dezessete mulheres, estavam reunidos na casa de um deles, Otávio Felix, realizando o culto dominical sob a direção do presbítero Saturnino, quando foram surpreendidos pelos magistrados da colônia de Abitina. É justamente em Abitinia que o grupo de cristãos enfrenta sua primeira "batalha" quando, liderados pelo presbítero Saturnino e pelo decurião Dativo, os fiéis foram levados à praça pública da cidade. Ao se negarem entregar as Sagradas Escrituras às autoridades, os fiéis garantiram a primeira vitória:

A esses dois (Dativo e Saturnino) seguiam o esquadrão do Senhor, em que brilhavam as armas do céu, o escudo da fé, a couraça da justiça, o elmo da salvação e a espada de dois fios da palavra de Deus (cf. $H b$.

\footnotetext{
${ }^{13}$ Ibid., II: Temporibus manque Diocletiani et Maximiani bellum diabolos christianis indixit isto modo, ut sacrosancta domini testamenta scripturasque diuinas ad exurendum pateret [...] Sed non tulit exercitus domini tam immane praeceptum sacrilegamque iussionem perhorruit et mox fidei arma corripuit, descendit in proelium, nom tam contra homines quam contra diabolum pugnaturus. (tradução nossa).
} 


\section{SEMINÁRIO DE PESQUISA EM CIÊNCIAS HUMANAS - SEPECH \\ Humanidades, Estado e desafios didático-científicos \\ Londrina, 27 a 29 de julho de 2016}

4,12): com tal proteção, eles garantiram a seus irmãos a esperança da vitória. ${ }^{14}$

Esse primeiro combate foi de suma importância na narrativa, uma vez que, outrora, naquele mesmo local, um antigo bispo da cidade, Fundano, havia entregado as Sagradas Escrituras para serem queimadas pelos magistrados locais. Algo que só não foi concretizado, graças a uma intervenção divina ${ }^{15}$.

Em seguida o autor narra a chegada dos cristãos a Cartago. Essa é a parte central do documento, uma vez que o autor apresenta o interrogatório, contendo os diálogos entre o procônsul Anulino e os cristãos (V-XVIII). Nesse momento do texto, o redator intercala suas reflexões às falas dos personagens, tecendo uma narrativa espetacular na qual os cristãos são chamados, um a um, a vencer o inimigo diabólico, resistindo à tortura e sofrendo o martírio em nome da fé.

$\mathrm{O}$ autor da passio descreve o interrogatório como uma verdadeira cena de horror, no qual os mártires são estendidos em cavaletes, e torturados com unhas de ferro e garfos gigantes. Na narrativa, o primeiro a ser interrogado foi Dativo, que afirmou ser cristão e ter feito parte da reunião, mesmo contra às ordens imperiais ${ }^{16}$. Após essa confissão, o autor da passio narra uma série de torturas infligidas a Dativo, pelos soldados imperiais, que só têm fim com a interrupção do mártir Tazelita, que afirma que todos são cristãos e fizeram parte da reunião. Após a tortura de Tazeliza, os oficiais se voltam para Dativo novamente: "Após Tazelita, o senhor designou Dativo para o combate, que estendido no cavalete, havia observado o corajoso combate de Tazelita"17. Do mesmo modo, quando Saturnino é convocado ao interrogatório, esse sente a "dureza dos combates" sofridos por seus companheiros ${ }^{18}$.

Após Saturnino, um a um, os cristãos são chamados ao interrogatório e às torturas. E em todos os casos, o martírio é identificado pelo autor como um combate ao Diabo: "[...] saltando para o combate o leitor Emérito"19; "Félix se adiantou para a batalha e com ele todo o exército do Senhor [...]"20; após esse, outro Félix o sucedeu no combate:

[...] na verdade, (Félix) depois de ter lutado com a mesma coragem, também, violentamente espancado com um pedaço de pau, entregou o espírito aos sofrimentos da prisão e se uniu ao martírio do Félix anterior ${ }^{21}$.

\footnotetext{
${ }^{14}$ Ibid., III: Hos agmen dominicum sequebatur in quo fulgebat caelestium splendor armorum, scutum fidei, lorica iustitae, saluationis galea et gladius bifrons sermo dei (cf. Herb. 4,12), quórum praesidio fulti apem uictoriae fratibus promittebant. (tradução nossa).

${ }^{15}$ Ibid., III.

${ }^{16}$ O édito de Diocleciano de 23 de fevereiro de 303 ordenava, entre outras coisas, a entrega das Sagradas Escrituras, bem como proibia a reunião de cristãos. Por isso que, ao interrogar o grupo, Anulino insiste em saber se cada um deles havia participado da reunião, e se possuíam as Sagradas Escrituras.

${ }^{17}$ Ibid., VII: Post hunc Datiuus a domino in certamen erigitur qui Tazelitae fortissimum proelium de próximo cominus, cum penderet ecúleo, spectarat extensus idemque cum se uoce saepius repetita christianum [...].(tradução nossa).

${ }^{18}$ Ibid., $\mathrm{X}$.

${ }^{19}$ Ibid., XI: Emeritus lector ad certamen exsiliens congrediente presbytero [...].(tradução nossa).

${ }^{20}$ Ibid., XIII: Sed cum Felix nomine et pasione processisset in proelium aciesque domini omnis incorrupta inuictaque perstaret [...]. (tradução nossa).

${ }^{21}$ Ibid., XIV: Pari etenim uirtute congressus, etiam ipse fustium illisione quassatus, animam intormenta carceris ponenes, superiores Felicis est martyrio copulatus. (tradução nossa).
} 


\section{SEMINÁRIO DE PESQUISA EM CIÊNCIAS HUMANAS - SEPECH \\ Humanidades, Estado e desafios didático-científicos \\ Londrina, 27 a 29 de julho de 2016}

Do mesmo modo: "Depois deles, lutou Ampélio, fiel guardião da lei das divinas Escrituras" ${ }^{22}$, "Maximiano, seguiu-o na confissão, e em luta semelhante, igual nos triunfos da vitória [...]"23. Também as mulheres são lembradas pelo narrador: “[...] todas as mulheres do grupo, com auxílio do Cristo Senhor, e na pessoa de Vitória, lutaram e foram coroadas" 24 .

Se sofrer o martírio era uma forma de combater o Diabo, quem era o Diabo a ser combatido? Na maior parte do interrogatório, é o próprio procônsul Anulino que ocupa esse papel. Em vários momentos do texto, Anulino é visto como um agente a serviço do Diabo, como nos demonstra as passagens do interrogatório de Tazelita e Saturnino, respectivamente:

Enquanto assim orava (Tazelita), o diabo, pela boca do juiz, lhe disse: O que devia ter feito era observar as ordens dos imperadores e césares.

Com o corpo cansado, mas vitorioso em sua alma, com palavras fortes e firmes proclamou o mártir:

Eu me preocupo apenas com a lei de Deus que aprendi. Essa é a que guardo, por ela vou morrer [...], fora dela nenhuma outra existe. (VI)

Em seguida, o procônsul lhe disse:

- Nesta que é a mais esplêndida cidade, eras tu, mais do que ninguém, quem deverias chamar os outros à razão, não descumprir os mandatos dos imperadores e césares!

Dativo, porém, com mais força e constância clamava:

Eu sou cristão!

Com essas palavras o diabo é vencido:

_Basta! - disse o procônsul. E imediatamente o enviou para o cárcere, reservando para o mártir o martírio que ele havia merecido ${ }^{26}$.

Em outras passagens é identificado como o próprio Diabo, como quando submete Saturnino, o jovem, filho do presbítero Saturnino, ao martírio:

Ouvindo o nome de "Salvador", Anulino se acende em ira e manda que preparem para o filho, o cavalete em que havia sofrido o pai. Com Saturnino estendido, disse-lhe o procônsul:

Que declara Saturnino? Vês onde foi colocado? Tem as Escrituras?

Saturnino:

${ }^{22}$ Ibid., XIV: Post hos suscepit certamen Ampelius, custos legis scripturarumque diuinarum fidelissimus conseruator. (tradução nossa).

${ }^{23}$ Ibid., XIV: Hunc sequebatur et Maximianus in confessione par, in congressione similis, in uictoriae triumphis aequalis. (tradução nossa).

${ }^{24}$ Ibid., XVII: [...] omnes feminae, Christo domino auxiliante, in Victoria congressae sunt et coronatae. (tradução nossa).

${ }^{25}$ Ibid., VI: Cui talibus oranti cum a diabolo per iudicem diceretur: "Custodire te oportuit iussionem imperatorum et Caesarum", defatigato iam corpore, forti atque constante sermone uictrix anima proclamauit: "Non curo nisi legem dei quam didici; ipsam custodio, pro ipsa morior [...] in lege dei praeter quam non est alia. (tradução nossa).

${ }^{26}$ Ibid., XIV. Tradução de Julio Cesar Magalhães de Oliveira (2010, p. 61). 


\title{
XI SEMINÁRIO DE PESQUISA EM CIÊNCIAS HUMANAS - SEPECH \\ Humanidades, Estado e desafios didático-científicos \\ Londrina, 27 a 29 de julho de 2016
}

\begin{abstract}
Eu sou cristão!
O procônsul:

Eu estou te perguntando, se participou da reunião e se tens $\overline{\text { Escrituras. }}$

Saturnino:

_ Eu sou cristão, e não há outro nome, depois do de Cristo, que devemos guardar como santo.

Inflamado o diabo com essa confissão:

Já que persiste - digo - em sua obstinação, é preciso submetê-lo, novamente, aos tormentos para que confesse se tens as Escrituras. ${ }^{27}$
\end{abstract}

Contudo, é interessante notar, que a ideia do martírio como um combate ao Diabo aparece, apenas, na fala do narrador. Em nenhuma passagem os fiéis se identificam como soldados de Cristo, ou mesmo parecem conceber o martírio como uma forma de combate ao Diabo. É uma concepção exclusiva do narrador, que busca ressignificar o martírio.

De fato, o autor da passio constrói sua narrativa de tal forma que, o interrogatório dos cristãos de Abitina pelo tribunal do procônsul Anulino é apresentado como uma grande batalha entre os mártires e o Diabo, no qual esse último é subjugado diante da postura firme dos mártires em defender sua fé. Sendo assim, a narrativa não poderia acabar se não dessa forma: "Aqui termina a luta do grande combate. Aqui o diabo é derrotado e vencido. Aqui os mártires de Cristo com gratidão, acolhem a glória eterna de sua paixão futura" 28

Esse "novo" significado que atribui ao martírio permite ao redator da passio, associar a Igreja donatista com a Igreja dos Mártires, que bravamente combateram ao Diabo. Se por um lado a Igreja dos Mártires é formada por aqueles que resistiram as tentações do Diabo e sofreram o martírio, por outro, os traditores são aqueles que, em comunhão com o próprio Diabo, traíram a Igreja.

E é dessa forma que o redator apresenta, já na conclusão do texto (XIX-XXIII), duas figuras centrais na origem do cisma: Mensúrio, que na época do martírio era bispo de Cartago, e Ceciliano, seu diácono. Para o autor da passio, tanto Mensúrio, quanto Ceciliano são os grandes traidores da história dos mártires de Abitina. Mensúrio é acusado pelo autor, de ter entregado as Sagradas Escrituras para serem queimadas ${ }^{29}$. Mas, mais grave do que isso, segundo o redator, tanto ele, como Ceciliano, foram os responsáveis pela morte dos mártires de Abitina.

Após o interrogatório diante do tribunal de Anulino, os mártires foram enviados à prisão, onde aguardavam pela sentença. Enquanto estavam na prisão, os

\footnotetext{
${ }^{27}$ Ibid., XV: Quo nomine saluatoris audito Anullinus exasit et in fium patrium instaurat eculeum; extensoque Saturnino: "Quid, inquit, Saturnine, profiteris? Vide ubi positus sis. Habes scripturas aliquas?" Respondit: "Christianus sum." Proconsul: "Ego quaero na conueneris et na scripturas habeas." Respondit: "Christianus sum: aliud non est nomen quod post Christum oportet nos sanctum obseruares." Qua confessione diabolus inflammatus: "Quoniam permanes, inquit, in obstinatione tua, etiam tormentis oportet te fateri an aliquas scripturas habeas". (tradução nossa).

${ }^{28}$ Ibid., XVIII: Hic certaminis magni pugna perficitur, hic diabolos superatur et uincitur, hic martyres Christi de passionais futurae gloria aeterna sum gratulatione laetantur. (tradução nossa).

Nessa passagem, o autor de refere a paixão futura, pois a maioria dos mártires morreu na prisão, enquanto aguardavam julgamento.

${ }^{29}$ Ibid., XX.
} 


\section{SEMINÁRIO DE PESQUISA EM CIÊNCIAS HUMANAS - SEPECH \\ Humanidades, Estado e desafios didático-científicos \\ Londrina, 27 a 29 de julho de 2016}

cristãos de Cartago se comoveram e procuraram ajudar os mártires levando comida e bebida, mas foram impedidos por homens armados que barravam sua entrada. Todavia, não eram os soldados imperiais que impediam que chegasse a ajuda aos mártires, eram membros da hierarquia da Igreja de Cartago. Segundo o autor, Ceciliano, seguindo as ordens de seu bispo, não permitiu aos fiéis de Cartago de prestar socorro aos mártires $(\mathrm{XX})$.

Dessa forma tanto Ceciliano, quanto Mensúrio não apenas se negavam a ajudar os mártires no cárcere, como impediam os fiéis de fazê-lo. Em diversas passagens, ambos são comparados ao próprio perseguidor: "Ceciliano se enfureceu como um tirano e um carrasco cruel"30; do mesmo modo: "De fato, (Mensúrio) tão desumano quanto um tirano, mais cruel que um carrasco [...]"31. Esses mesmos termos são usados pelo narrador, para representar Anulino, ou mesmo os imperadores ${ }^{32}$. Na visão do redator, Mensúrio e Ceciliano são tão diabólicos quanto o próprio Anulino pois, se este causou sofrimento aos mártires, pior fizeram eles que os condenaram à morte:

Finalmente, como nem Mensúrio, nem seu diácono Ceciliano quiseram parar como aquela crueldade monstruosa, o procônsul Anulino e os outros perseguidores, que nesse meio tempo estavam ocupados com outros assuntos, os mártires abençoados, privados de alimentos corporais, pouco a pouco, e no intervalo de dias, renderam à sua condição natural sob a restrição de excruciante fome, e foram para o reino dos céus com a palma do martírio $[\ldots]^{33}$.

Mas antes de partirem, os mártires, segundo o redator, se reuniram em "concílio" no cárcere e julgaram aqueles que em comunhão com o perseguidor, traíram a sua Igreja. Em seu pequeno concílio ${ }^{34}$, os mártires deixaram uma ordem a seus descendentes, de que renovassem o nome cristão e se separassem dos impuros e traidores ${ }^{35}$. Segundo o redator eles sentenciaram: "Se qualquer um entrar em comunhão com os traidores, ele não participará conosco do reino do céu" "36. E a partir da sentença dos mártires, criou-se em definitivo a separação entre a santa "Igreja dos Mártires" e a poluída "Igreja dos Traidores":

A Santa Igreja segue o exemplo dos mártires e amaldiçoa a traição do traidor Mensúrio [...] Que pessoa [...] pode pensar que a igreja dos

\footnotetext{
${ }^{30}$ Ibid., XX: Caeciliano saeuient tyranno et crudeli carnifice. (tradução nossa).

${ }^{31}$ Ibid., XX: Etenim hic tyranno saeuitor, carnifice crudelior [...]. (tradução nossa).

${ }^{32}$ Para Maier (1987, p. 86-87), nessa passagem, o termo tirano refere-se ao imperador Maximiano Augusto, enquanto o carrasco é o procônsul Anulino. Segundo o autor, essa interpretação serve para todo o texto, exceto para as passagens 13 e 18, no qual o "tirano" é indiscutivelmente o procônsul Anulino.

${ }^{33}$ Ibid., XXIII: Postremo cum nec Mensurius nec minister eius caecilianus ad hac immani crudelitate cessare uellent, Anullino proconsule aliisque persecutoribus interim circa alia negotia occupatis, beati martyres isti corporeis alimentis destituti paulatim et per interualla dierum naturali conditioni, famis atrocitate cogente, cesserunt et ad sidérea regna sum palma martyrii migrauerunt [...].(tradução nossa).

${ }^{34}$ Para Maier (1987, p.88), a ideia de um concílio no cárcere parece um tanto exagerada. Todavia, o redator não teria, necessariamente, inventado o texto que, provavelmente, deve ter sido baseado em uma carta, escrita pelos mártires do cárcere.

${ }^{35}$ Ibid., XXI.

${ }^{36}$ Ibid., XXI: Si quis traditoribus communicauerit, nobiscum partem in regnis caelestibus non habebit. (tradução nossa).
} 


\section{SEMINÁRIO DE PESQUISA EM CIÊNCIAS HUMANAS - SEPECH \\ Humanidades, Estado e desafios didático-científicos \\ Londrina, 27 a 29 de julho de 2016}

mártires e o conventículo dos traidores são um e a mesma coisa? Ninguém! As duas são absolutamente hostis uma com a outra! Elas são opostas entre si como a luz e a escuridão, a vida e a morte, o santo anjo e o diabo, Cristo e o Anticristo $[\ldots]^{37}$.

A partir dessa análise é possível inferir que a Paixão dos Mártires de Abitina é uma narrativa que remete às origens do cisma a partir do ponto de vista donatista: Ceciliano traiu a Igreja e em associação com o Diabo entregou os mártires à morte. Essa construção narrativa permite ao redator reivindicar uma identidade coletiva para o grupo da qual faz parte, mas, também, conferir uma identidade ao inimigo religioso.

Como bem ressaltou Shibutani (1966, p. 190), o conceito do que é o inimigo, é construído com frequência, pela projeção sobre ele de todos os atributos mais odiados ou desprezado, pela visão de um dos lados em termos idealistas. Enquanto um dos lados é dotado de todas as virtudes nobres, lutando de forma altruísta por uma causa digna. $\mathrm{O}$ inimigo é percebido como a personificação viva de tudo que é condenável.

Dessa forma, os donatistas são apresentados como descendentes dos mártires, que nos tempos de perseguição combateram e subjugaram o Diabo. Enquanto os cecilianistas, como descendentes de Ceciliano, são associados aquilo que existia de mais condenável entre os cristãos do período: a traição e o colaboracionismo com o perseguidor e, consequentemente, com o próprio Diabo.

Ao evocar uma memória dos mártires, o autor reforça uma questão central na construção da identidade desse grupo: a identificação da Igreja dissidente com a "Igreja dos Mártires", no qual "nós" somos a Igreja dos mártires, por isso a Igreja dos que sofreram perseguição, e "vocês" são a "Igreja dos Traidores", que "nos" persegue. Dessa forma, o autor buscava demonstrar porque os donatistas estavam certos em persistirem no cisma. Afinal, assim como os mártires resistiram ao perseguidor, e as tentações do Diabo, também eles deveriam resistir às leis imperiais que pretendiam estabelecer a união.

Ao clamarem por uma relação com os mártires de Abitina, os donatistas davam significado a sua luta, mesmo após a "derrota" de 411 (DEARN, 2004). Esse significado está relacionado a própria ideia de combate ao Diabo. Pois, assim como ordenaram os mártires, era necessário não apenas se manter impoluto do crime de traição, mas da própria comunhão com os “cristãos" poluídos. Esse é um discurso ativado em um momento específico, quando são colocados na ilegalidade, e por isso precisam reforçar a sua identidade enquanto grupo, bem como suas posições.

\section{CONSIDERAÇÕES FINAIS}

Por meio da análise desse texto é possivel um esforço do autor donatista em moldar uma identidade coletiva em oposição aos "outros", ou seja, aos cecilianistas. Eles eram a Igreja dos Mártires, enquanto os cecilianista eram dessendentes de um

\footnotetext{
${ }^{37}$ Ibid., XXII: Exinde ecclesia sancta sequitur martyres et detestatur Mensurii perfidiam traditoris [...] et unum atque idem esse existimet et ecclesiam martyrum et conuenticula traditorum? Nemo scilicet, quoniam haec inter se ita repugnat contrariaque sunt sibi ut lux tenebris, uita morti, sanctus angelus diabolo, Christus Antichristo [...].(tradução nossa).
} 


\section{SEMINÁRIO DE PESQUISA EM CIÊNCIAS HUMANAS - SEPECH \\ Humanidades, Estado e desafios didático-científicos \\ Londrina, 27 a 29 de julho de 2016}

traidor, portanto, a Igreja dos Traidores. Mas, também, era uma forma de definir as fronteiras que os separavam do grupo opositor. Assim como os mártires do passado, os donatistas devereriam resistir à perseguição imposta pelo Diabo, ou seja, resistir às leis que os obrigavam a unir-se aos traidores. Percebe-se, desse modo, um esforço em deslegitimar as ações se seus inimigos, os classificando não apenas como perseguidores, mas como diabólicos. Contudo, não podemos perder de vista que a demonização do adversário, tal como ocorre nessa narrativa, ocorre em um momento específico do confronto e atende a usos estratégicos. É, sobretudo, um discurso ativado quando era necessário reforçar o senso de comunidade, bem como as fronteiras que os separavam dos "outros".

\section{REFERÊNCIAS}

Passio Datiui, Saturnini presbyteri et aliorum. In: RUIZ BUENO, D. (ed.). Actas de los mártires. Madri: Editorial Católica, 1962.

Passio Datiui, Saturnini presbyteri et aliorum. In: MAIER, Jean-Louis. Le Dossier du Donatisme. Vol. I: Des origines à la mort de Constance II (303-361). (Texte und Untersuchungen zur Geschichte der altchristlichen Literatur, 134). Berlim: AkademieVerlag, 1987.

BROWN, P. Santo Agostinho: uma bibliografia. Tradução de Vera Ribeiro. Rio de Janeiro: Editora Record, 2005.

BURKE, P. Testemunha Ocular. Bauru: Edusc, 2004.

CORNELL, T; MATTHEWS, J. Roma. Legado de um Império. Vol.II. Tradução de Maria Emília Vidigal. Madri: Edições Del Prado, 1996.

DEARN, Alan. The Abitinian Martyrs and the Outbreak of the Donatist Schism, Journal of Ecclesiastical History, 55/1, 2004, pp. 1-18.

FRANCHI DE' CAVALIERI, Pio. Note agiografiche. Studi e Testi, Cidade do Vaticano, v. 65, pp. 1-71, 1935.

FREND, William Hugh Clifford. The Donatist Church: A Movement of Protest in Roman North Africa. Oxford: Oxford University Press, 2003.

MAGALHÃES DE OLIVEIRA, J. C. Dos arquivos da perseguição às histórias dos mártires: hagiografia, memória e propaganda na África romana. História (São Paulo), vol. 29, n. 1, p. 56-70, 2010. 


\section{SEMINÁRIO DE PESQUISA EM CIÊNCIAS HUMANAS - SEPECH \\ Humanidades, Estado e desafios didático-científicos \\ Londrina, 27 a 29 de julho de 2016}

Vbi ecclesia? Basiliques chrétiennes et violence religieuse dans l'Afrique romaine tardive. In: FREU, C.; JANIARD, S. (éds.) Mélanges Jean-Michel Carrié, Bibliothèque de l'Antiquité Tardive (inédito).

MONCEAUX, Paul. Histoire litte'raire de l'Afrique chre'tienne depuis les origines jusqu'a l'invasion arabe, t. 3: Le IVe siècle, d'Arnobe à Victorin. Paris, E. Leroux: Paris, 1905.

SHAW, Brent D. Sacred Violence: African Christians and Sectarian Hatred in the Age of Augustine. Cambridge; New York: Cambridge University Press, 2011.

SHIBUTANI, T. Improvised News: A Sociological Study of Rumor. Indianápolis: The Bobbs-Merril Co, 1966. 